\title{
Agenda informativa y ciudadanía
}

Por Giselle Munizaga

\section{Democracia y discursos de reconocimiento}

La integración política supone crear horizontes interpretativos comunes en el interés de los cuales discutir públicamente. Para que una sociedad pueda tener conciencia de sí misma y por lo tanto existir como tal, inserta en una identidad y en un proyecto de futuro colectivo, debe ser capaz de generar lo que Habermas llama discursos de autocomprensión:

"Controversias en las que los participantes se aclaren, por ejemplo, cómo quieren concebirse como ciudadanos de una determinada república, como habitantes de una determinada región, como herederos de una determinada cultura, qué tradiciones quieren continuar o romper, cómo quieren relacionarse con su destino histórico, etc." (1)

y por supuesto, también poder discutir y llegar a acuerdos acerca de temas más concretos como la salud, la educación, el cómo resolver los problemas de la seguridad ciudadana.

Muchos en Chile piensan que la plena democracia es todavía un sueño lejano. Las profundas huellas dejadas por el autoritarismo siguen marcando no sólo los espacios institucionales políticos y sociales sino, además, el desarrollo de la vida cotidiana de los habitantes de este país. No hemos logrado un sistema de representación política inclusivo, no hemos sido capaces de elaborar las diversas visones del pasado y, lo que es mas grave, no hemos restituido los tejidos sociales fundamentales. Es decir, no hemos conseguido afincar las bases necesarias para restablecer y fortalecer los sentimientos de pertenencia común que son la base de la vida ciudadana. El extrañamiento, la marginación y la indefensión siguen profundamente instaladas en un escenario nacional que parece privilegiar únicamente los itinerarios individuales.

Ello es en parte producto de los "amarres constitucionales", los cuales distorsionan la representación y el poder político; pero también, y en gran medida, de la falta de discursos de reconocimiento, bases fundamentales sobre las cuales descansa la ciudadanía tanto su concepción como su ejercicio efectivo. Discursos de reconocimiento donde se establecen los componentes de la identidad nacional en tanto pertenencia a un común origen y destino, donde se elaboran los elementos de una conciencia de lo colectivo que posibilita la valoración del bien y el interés general, donde se fijan aquellos significados y sentidos de la participación social y política sobre los cuales descansa la responsabilidad del propio involucramiento (activo y no puramente demandante o crítico) en los problemas y tareas sociales. Discursos de reconocimiento que no sólo refieren a las esferas valóricas o idealizadas del ser humano, sino que surge de la conciencia socializada de cada individuo en tanto su experiencia le señalan que el egoísmo social tiene siempre un costo personal y que su bienestar individual y privado pasa necesariamente por los otros.

Se puede afirmar que en Chile no se han generado los discursos fundamentales para la recomposición de la cultura política y ciudadana y que sin éstos nos enfrentamos a orden democrático frágil. Basta observar las controversias que se han producido últimamente a propósito de problemáticas sociales urgentes en las que se pone en juego el bienestar básico de las personas como son la cesantía, la seguridad ciudadana o la contaminación ambiental. No vemos en ellas la expresión de una voluntad destinada a encontrar las mejores soluciones y a comprometerse responsablemente en su logro. Lo que se hace presente es la acusación descalificadora que deja al adversario fuera de toda posible confrontación y por lo tanto de toda convergencia. Discurso de negación y expulsión donde se hace imposible el reconocimiento del otro. Discurso donde está ausente todo interés o intensión de lograr acuerdos y lo que se busca es "asesinar" o "exterminar" políticamente al oponente. Es decir, un cuadro comunicacional que recuerda las polarizaciones disruptivas a que se llegó en el pasado. 


\section{El espacio comunicativo chileno y la debilidad de lo público}

La ausencia o debilidad de los discursos socio-políticos de reconocimiento se puede explicar en importante medida por las características actuales del espacio comunicativo chileno. La comunicación social, es decir, aquella que tiene efectos en la socialización e integración de los individuos que componen el todo social, no cumple los requisitos necesarios para ser comunicación pública. Una comunicación social llega a ser comunicación pública no sólo cuando esta sometida a una publicidad amplia y es accesible al conjunto de la sociedad. La comunicación adquiere su estatus público cuando en ella se producen intercambios simbólicos constitutivos de realidades colectivamente compartidas en las que la diversidad es aceptada y valorada. También cuando en ella se da lugar a las versaciones y versiones de lo aceptado como apropiado y se abren los espacios para establecer las bases morales de la vida en común. Así mismo, cuando la comunicación permite el entendimiento y la elaboración de las definiciones y procesos del mundo compartido que es diferente al mundo privado poseído en él.

El espacio comunicativo esta lejos de ser un lugar para la información, el conocimiento y la evaluación racionalizada de lo general. La comunicación social está hoy en día dominada por una lógica discursiva de mercado en la que predomina una meta de posicionamiento dentro de una trama fuertemente estandarizada. Para constituirse en actor social es necesario adecuarse a las reglas de la publicidad: saber vender y poder venderse hablando de temas de "moda" en cualquier espacio comunicativo que se tiene al alcance. Lo que se privilegia es la aparición. Es decir, lograr la más amplia y frecuente exhibición en el escenario público, llamando la atención y concitando adhesión respondiendo a deseos y sensibilidades primarias o coyunturales de la población, sin que importen tanto los significados y finalidades de lo que se dice. La comunicación social ya no está fundamentalmente dirigida a producir el conocimiento mas acabado acerca de los asuntos públicos y con ello a movilizar el entendimiento racional de los ciudadanos. Existe un círculo perverso que encierra a las temáticas y actores que tienen acceso a los medios masivos, los cuales constituyen el ámbito de difusión de comunicación más importante. La falta de propuestas interpretativas diversas y de debates reales enfrenta a los medios de prensa a un escenario empobrecido. Estos no encuentran un alimento sustantivo en los discursos de una sociedad política poco transparente respecto a sus posturas, que habla en medias palabras, utiliza la deslegitimación y evita las confrontaciones ideológicas; Tampoco en las voces de una sociedad civil que no logra articular discursos que vayan más allá de aspectos coyunturales reivindicativos.

Ante la necesidad de ofrecer a sus públicos escenarios de realidad resonantes y atrayentes, los medios presentan aquellos aspectos del acontecer nacional que parecen preocupar a las mayorías: problemas directamente vinculados con la vida cotidiana y el bienestar individual. Estos problemas integran las agendas periodísticas dentro de una óptica casuística: el caso de la prueba Simce, el caso de la venta de drogas en Bellavista, el caso Matute, el caso del mal rendimiento de la selección de fútbol. El relato periodístico se construye mostrando los aspectos más dramáticos y a las víctimas de los sucesos; buscando establecer un cuadro de demandas y críticas a las autoridades y enfrentando fragmentos de opiniones políticas incompletamente recogidas. Faltan visiones contextuales, voces de expertos, diagnósticos y proyecciones analíticas. Los propios periodistas están atrapados en la lógica del posicionamiento y la venta; y, a menudo, caen en un protagonismo que nubla el papel de inductores que deberían privilegiar.

Sin embargo, no se debe pensar que el discurso publicitario de mercado, que se ha vuelto dominante en la prensa, anula la gravitación de los posicionamientos ideológicos. Las posturas doctrinales se hacen presentes a través de acentos sutiles dentro de relatos dramáticos 0 conflictivos, mediante proximidades y relaciones que inducen a determinadas semantizaciones, utilizando tratamientos preferenciales o voceríos descalificadores, etc. $Y$ está claro que el sistema de medios chileno, monopolizado por sectores de derecha, introduce en los discursos sociales, en la representación de la realidad nacional, indudables sesgos ideológicos. Establece las formas como los acontecimientos son tematizados y sitúa las ideas fuerzas en torno a las cuales se recogerán las diversas opiniones. Por ejemplo, ante casos de venta de drogas sé tematiza la amenaza a la seguridad ciudadana, relacionando 
consumo con delincuencia e instituciones de orden (policías y tribunales) con incompetencia o corrupción. Las ideas-fuerzas predominantes son la necesidad de mano dura, de aumento del control represivo, de identificar, aislar y castigar a los consumidores en cuanto corruptores contagiosos. Es decir, se escenifica el mal social únicamente como desviación individual.

La debilidad de comunicación pública que se observa en la sociedad chilena es producto de varias circunstancias. En primer lugar de la fuerte y larga intervención del régimen militar en los procesos de comunicación social. En segundo lugar de la falta de implementación de políticas de comunicación "reparadoras" en los gobiernos de la Concertación. En tercer lugar de la debilidad histórica y el creciente deterioro de la cultura ciudadana que se traduce en falta de participación y organización social y en ausencia de compromisos y responsabilidades colectivas.

\section{El régimen militar y la ruptura de lo público}

El gobierno militar nos lega, por decir lo menos, una comunicación social gravemente dañada. En éste ámbito, como es propio de los regímenes totalitarios, se hace sentir toda la fuerza represiva de una autoridad que no sólo busca imponer su propio proyecto económico-social sino, además, refundar la patria y hacer prevalecer una chilenidad "verdadera y sana".

La meta refundacional requiere establecer el dominio de los discursos oficiales en sus vertientes nacionalista-autoritaria y neoliberal-mercantilista y, evitar la emergencia de otras interpretaciones de mundo. Entonces, una tarea urgente es la vigilancia-represiva para acallar cualquiera voz, no sólo aquella disidente sino, además, cualquiera distinta a la propia. La represión es funcional para ejercer un control sobre los discursos sociales, sobre lo que se dice y no se dice públicamente, sobre lo que está destinado a ser escuchado por todos. Los métodos son la clausura y control de los espacios comunicativos, la censura de contenidos y la persecución de personas. A la dictadura le preocupa particularmente mantener un control sobre los medios de comunicación y una vigilancia alerta y permanente sobre los espectáculos de llegada masiva.

Es así como durante largos años los chilenos encuentran en la agenda de los medios masivos la representación de una realidad plana y monocorde, sólo sacudida por los ritos celebratorios del desarrollo patrio, los triunfos y las vicisitudes deportivas, y las traumáticas imágenes de un mundo en crisis frente a la cual Chile aparece como una isla de paz. La voz oficial se constituye en el gran discurso a partir del cual se modulan los otros discursos sociales validados, mientras que, con el ejercicio de la represión y la censura, se limita la emergencia de discursos distintos.

El resultado es que durante el gobierno militar los medios de comunicación ofrecen a los chilenos la representación engañosa y reduccionista de un mundo de vida sin mayores complejidades ni ambigüedades. Se instala un orden interpretativo que mira los acontecimientos en términos de blanco-negro, bueno-malo, correcto-incorrecto. Con ello se consigue un disciplinamiento comunicativo que en algún nivel opera como una droga segurizante en una sociedad en la que está vigente el miedo a la polarización, el fantasma del caos.

Pero, por debajo de los aspectos tranquilizantes que conlleva el imponer en lo público un simulacro de orden, las dinámicas represivas producen en las personas una profunda y perdurable inseguridad interna que se manifiesta en lo comunicativo. El disciplinamiento es intimidante y contagioso; hace que el miedo y la autocensura inunden el espacio social y, por lo tanto, afecta en niveles muy profundos las libertades expresivas de los individuos y grupos sociales. Se introduce, hasta en el habitante más anónimo y privado, la desconfianza del otro. El silencio pasa a ser la consigna porque se prefiere evitar que se conozca el propio pensamiento. Se privilegia el sumarse al decir generalizado porque se teme al desacuerdo. El miedo al discurso abierto impregna las redes de comunicación de todas las esferas del quehacer social (familiares, vecinales, laborales, recreativas, etc.) afectando las expresiones de pertenencia, participación y las identidades sociales. 
Sin embargo, los triunfos y heridas de la represión nunca son totales. Siempre los pueblos se niegan a aceptar sin resistencia los amordazamientos y los ensordecimientos y en el caso chileno es así. A pesar de la permanente persecución y la amenaza manifiesta vemos como durante la dictadura se produce el fenómeno de la "otra comunicación", aquella que se niega a aceptar la falta de libertad en el decir y busca informar acerca de lo silenciado para establecer las propias visiones sociales. Por un lado ella es producto de la continua lucha informativa de algunos medios y periodistas que aprovechan los frágiles resquicios de libertad para intervenir en el ámbito comunicativo masivo Por otro, tiene su raíz en la sociedad civil, emerge de pequeños grupos, muchas veces efímeros, de estudiantes, pobladores, mujeres, trabajadores, cultores de artes, etc., que se caracterizan por su preocupación de hacer de la comunicación una forma importante de la propia existencia. Estos grupos generan limitadas redes de comunicación a través de reuniones sociales, eventos artísticos, hojas literarias, periódicos artesanales; catacúmbicos corredores donde se formulan y difunden no sólo discursos de resistencia sino, además, discursos conteniendo proyectos de un mañana distinto.

En este precario y muchas veces evanescente sistema comunicativo paralelo se expresa la voluntad de sobrevivencia ciudadana y política de muchos sectores sociales. Voluntad que teje redes de comunicación cara a cara entre aquellos que son capaces de reconocerse como parte del disenso y que pone en juego, las diversas creatividades comunicativas y artísticas para representar y compartir las experiencias comunes de encierro, marginación, persecución. Las situaciones de sobrevivencia producen fuerzas vitales poderosas. En las comunicaciones la urgencia de evitar el silenciamiento opera como un aliciente al deseo de expresión. Lástima que esta pulsión no siga vigente cuando con la democracia se restablecen espacios de comunicación social. Lo que podemos observar es una delegación del habla en la autoridad, se espera que ella defina la situación y responda acerca de los problemas. En el decir público la voz oficial pasa a ser la más valedera y legítima.

Esa fue la herencia comunicacional de dos caras que dejó el gobierno militar y que constituyó el terreno sobre el cual se fundaron los proyectos y las esperanzas de redemocratización de las comunicaciones. Por un lado las heridas a reparar para restablecer un discurso público plural, inclusivo y abierto al debate: el desmembramiento de las redes de intercambios sociales institucionalizadas con la consiguiente decadencia comunicativa de sus actores y discursos; el estrechamiento del sistema de medios desde el punto de vista de su representación social y política; y, lo más estructural, el deterioro de las libertades y seguridades comunicativas de los chilenos. Por otro, los logros a salvaguardar: las voluntades y luchas por decir a pesar de la imposición autoritaria y la puesta en juego de múltiples creatividades y lenguajes innovadores.

\section{Los proyectos de la Concertación}

Cuando, al comienzo de la transición, se formulan los proyectos y programas de la Concertación en lo que se refiere a las comunicaciones, la mirada se focaliza en la necesidad de revertir los efectos represivos del régimen militar. Entonces interesa principalmente el restablecimiento de la libertad de expresión mediante la eliminación de todo control gubernamental sobre los medios. También existe una voluntad de constitución de un sistema de medios más amplio y diverso, el cual es visto como un logro natural de la recomposición democrática y también como resultado de políticas de fomento. Así mismo se propone la instauración de medidas para el fortalecimiento profesional de los comunicadores. Hay conciencia que se han producido profundas transformaciones estructurales en el sistema de comunicación producto de los desarrollos tecnológicos y de las modernizaciones. Transformaciones que se hacen presentes sobretodo en algunos sectores del sistema medial y tienden a profundizar las tendencias a la centralización y a la concentración. También existe un reconocimiento de la creciente gravitación de dinámicas proveniente de un modelo económico que necesita de la publicidad para un buen funcionamiento del mercado y que modifican, por imperativo los de la venta, las lógicas discursivas y formales. Sin embargo, se piensa que es posible establecer medidas y regulaciones en pro de un acceso y control mas ampliado y diverso del sistema y de una mayor libertad y pluralidad de la comunicación social. 
Cuando se instala el primer gobierno de la Concertación se recogen en lo general los principios de democratización, pero se apuesta al mercado como mejor mecanismo para salvaguardar la diversidad y el pluralismo informativo, social y cultural, en los medios. Además existe una particular preocupación por evitar el control o injerencia gubernamental sobre medios, para no caer en prácticas dirigistas o totalitarias, lo que se expresa en las reglamentaciones de la Televisión. Si bien se ponen en marcha proyectos de modificaciones legales, pensadas para perfeccionar la libertad de expresión y un mejor ejercicio profesional, como la Ley de Prensa, éstas todavía no logran ser implementadas.

La falta de logros democratizadores en el campo de las comunicaciones está presente en el diagnóstico contenido en el documento de junio de 1999 donde se establecen las bases programáticas para un nuevo gobierno de la Concertación. En éste se señala:

"Hasta ahora, durante los dos gobiernos de la Concertación, se ha postergado o soslayado este importante problema (lograr que el modelo político, económico y cultural sea concordante son su sistema comunicacional) dejando al mercado como el gran arbitrador de las políticas comunicacionales".

Allí se sostiene que:

"Es el derecho social a la información el que sustentará políticas de Estado destinadas a regular el mercado de las comunicaciones sociales, crear medios, fomentar la producción y dar espacios para la creación y participación de todos los ciudadanos en el sistema cultural del país y la exigencia de que el periodismo sea ejercido por profesionales"(2).

Es posible entonces concluir que el grupo que hasta ahora ha liderado la transición no se ha interesado verdaderamente 0 no ha juzgado necesario impulsar actos políticos de recomposición de la comunicación pública que, como hemos visto, fue profundamente violentada durante el régimen militar. La postura gubernamental ha sido, dentro del lema que la mejor política comunicativa es la no política, dejar operar el mercado y hacer descansar en la operación de medios masivos sometidos a un mínimo de regulaciones las tareas de proporcionar los escenarios de realidad a partir de los cuales proyectar las vidas individuales y colectivas. Ausentes han estado las ideas que visualizan los procesos comunicativos públicos como empresas colectivas y vinculan su ampliación y robustecimiento al logro de metas de integración, de desarrollo, de bien común. Lo que ha primado es la concepción de la comunicación pública como un ejercicio particular y un producto transable. La comunicación pública ha sido fundamentalmente vista como un producto dirigido a consumidores individuales. Las personas a través de sus consumos estarían señalando qué mensajes producir y de esta manera los medios y los actores sociales y políticos, a ellos convocados en virtud de su capacidad de rating o demanda, estarían satisfaciendo democráticamente las necesidades sociales.

La postura de los partidos y personeros políticos de la Concertación, aunque algunas pocas veces crítica, tampoco ha reflejado deseos sistemáticos de políticas de fomento de un espacio comunicativo democratizado. No encontramos en este sector un involucramiento activo en iniciativas destinadas a recomponer un ámbito discursivo público poco representativo de una realidad social y política altamente compleja y contradictoria. Falta comprensión y voluntad política frente al tema o existe temor a expresar ideas que puedan ser tildadas de intervencionistas. En épocas de elecciones o ante situaciones de crisis surgen quejas. Se reacciona frente a las ofensivas de una derecha ideologizada que, contradiciendo sus pronunciamientos de resguardo de la gobernabilidad y la paz social, enarbola discursos deslegitimadores y polarizadoras los cuales encuentran una amplia cobertura y un propicio eco en medios de prensa mayoritariamente alineados con sus intereses. Sin embargo, las preocupaciones se olvidan en los tiempos de una aparente normalización de los discursos. Parece dejarse de lado las iniciativas destinadas a establecer un marco comunicativo donde se tienda a resguardar los valores de la libertad de expresión y el pluralismo, más allá de la pura operación del mercado, y donde se pongan acentos en los aspectos colectivos políticos, sociales y culturales de las comunicaciones públicas. No se observa un intento de enriquecimiento del diálogo ciudadano a través de las tematizaciones y de las interpelaciones 
que realiza el mundo político que parece estar encerrado en el círculo limitante de consensos económicos y políticos concebidos como intocables. Las interlocuciones están dirigidas a aquellos que detentarían las cuotas más significativas del poder económico, político y militar tal como establecido y podrían poner en peligro la gobernabilidad o el progreso. Se conversa con ellos y dentro de los términos por ellos establecidos. Es cierto que también existe una preocupación, que a menudo refleja una intensión de posicionamiento personal, por atender a la gente pero como sujetos de problemas específicos y coyunturales, no como ciudadanos participes en una empresa de construcción política.

Tampoco en la sociedad civil se observa una conciencia adecuada respecto al establecimiento de un espacio comunicativo y un discurso público ciudadano. Escasos son los grupos de opinión y personas que, desde una óptica analítica y contextualizadora, se hagan cargo de dar cuenta de la marcha del país y de los problemas derivados de ella, alimentado debates posibles. La representación de necesidades e intereses se realiza de manera focalizada y obedeciendo a aspectos coyunturales del acontecer nacional.

\section{Los falsos escenarios}

Ya sea por las herencias dejadas por el gobierno militar en las comunicaciones sociales, ya sea por insuficiencias de los gobiernos y de los actores políticos de la Concertación, ya sea por debilidades de la propia sociedad civil, lo cierto es que en Chile todavía no se ha logrado reconstituir un ámbito comunicativo público democratizado. El discurso social hegemónico de la transición ha tendido a velar y opacar más que a mostrar las complejidades y dificultades de un proceso en el que la compleja comprensión del presente y el pasado y la elaboración de horizontes interpretativos comunes son fundamentales. Lo que ha primado en él, es la representación de un consenso no sólo respecto al modelo económico sino que también a diversas cuestiones políticas, sociales y culturales. Consenso engañoso por su carácter impositivo, vendido como fundamental para dejar atrás los traumas del pasado y fijar la mirada en un futuro promisorio. Las capacidades comunicativas han estado constreñidas por la vigencia de principios castradores. Manifestar él más simple desacuerdo en materias concretas ha sido visto como signo de conflictividad, de ingobernabilidad, de ruptura del orden. Mas combatida aún es la expresión de una visión social contraria al modelo vigente, la cual ha sido descalificada como añeja, como poco moderna. Ha operado una suerte de represión, distinta a la del régimen militar, que estigmatiza y margina las voces de las diferencias en tanto atentatorias al proyecto de reconstitución democrática.

Las limitaciones de un sistema de medios, donde no se resguarda el acceso ampliado y la diversidad, con la consecuente gravitación de un discurso oficial reduccionista, sin contrapartes, se refleja en los escenarios de país ofrecido a los chilenos. Realidades masmediadas que tienen un importante peso en los procesos de elaboración de opiniones y en la formación de la conciencia ciudadana. Frente a la pregunta qué es lo que cotidianamente ha estado en las agendas informativas de los medios podemos concluir lo siguiente. Las agendas periodísticas de la transición han estado marcadas por dos características: por un lado, ha operado una selección sesgada de lo noticiable; por otro, se ha tendido a minimizar el tratamiento de temáticas que refieren a aspectos fundamentales de la recomposición social y que tienen que ver principalmente con la elaboración del pasado y las diferentes lecturas que se hacen de él.

El componente central y permanente del recuento del acontecer nacional ha sido, durante muchos años, el fútbol. Las competencias entre equipos, los comentarios acerca de los desempeños de los jugadores, la suerte en el extranjero de figuras convertidas en ídolos nacionales, tienden a copar espacios privilegiados en los informativos de la televisión y la radio y ha producir una suerte de futbolización de la agenda de la prensa escrita. Así mismo y mayoritariamente en los medios de consumo más masivo, se hace diariamente un detallado recuento de una multiplicidad de hechos policiales y accidentes, en los que las víctimas y sus perdidas tienen un papel destacado.

Es decir, lo que está siempre presente en la agenda periodística es fútbol y crímenes. Con el fútbol se proyecta un escenario de realidad donde se enfrentan equipos dotados de historias y 
perfiles propios que ponen en juego atributos de fuerza, competitividad, poder y victoria. Cualquiera que haya escuchado comentarios futbolísticos sabe que el fútbol proporciona una realidad compleja en su evaluación y altamente debatible que da lugar a muy diferentes discursos y visiones. El fútbol estimula un apasionado debate entre la gente, a través del cual se elaboran sentimientos de pertenencia y se canalizan frustraciones e ilusiones. Por otro lado con el relato casuístico de los crímenes, siempre concretos, siempre con resultados de perdidas, de daños visibles, de víctimas, se hace un señalamiento conjurante de las fuentes de amenaza social. La información policial sitúa el bien y el mal, el orden y el desorden y junto con ello legitima la represión y la negación de los "otros" estigmatizables, los delincuentes, los marginales; a la vez se ensordece los temores respecto a otras fuentes de inseguridades sociales y personales. Se le proporciona un lugar social definible a la amenaza, a la desconfianza.

Pero en lo que dice a las áreas temáticas más posesionadas en la agenda informativa y que tienen un mayor peso en el imaginario público, lo analizado no es todo. Al escenario anterior se suma en los primeros años de la transición, otro componente. Durante estos años vemos que reciben una importante cobertura los hechos relacionados con el llamado progreso del país, sobre todo aquellos vinculados con los desarrollos y estabilidad de la marcha económica. Con estas noticias se pone en juego un discurso legitimador del modelo en el cual se hace depender la estabilidad del país y el bienestar social en los éxitos logrados en el terreno de la economía. Lo que se proyecta es la imagen de Chile país "tigre" que ha dejado atrás el subdesarrollo. La contraparte es el no tratamiento de la permanencia de la pobreza, de la desigualdad desintegradora, de la precariedad en cuestiones fundamentales para el bienestar social, etc. Realidades que sólo aparecen como casos curiosos (la mujer gallina), como tragedias individuales (guaguas abandonadas) y cobran mayor visibilidad y se generalizan ante situaciones de catástrofes climáticas (aluvión, temporales) o de otro tipo (mineros atrapados en derrumbe).

Por otro lado si queremos fijarnos en las ausencias, en aquello que se prefigura deficientemente en el escenario de realidad masmediado, debemos subrayar la presencia muy disminuida de aquello que concierne al campo propiamente político. Es decir, el juego de la política en su función de representación y mediación. En el discurso informativo ha sido insuficientemente representado el parlamento en tanto institución fundamental de un estado democrático. No se han dado a conocer los desarrollos de los proyectos de ley y los debates producidos en torno las diversas alternativas. Por otro lado, en lo que dice relación a los partidos y conglomerados políticos, no han estado presentes elementos discursivos que proporcionen identidad a estas instituciones en tanto elaboradoras de diagnósticos críticos y detentoras de distintas propuestas sociales y culturales. Las instituciones y actores del campo político han tendido a concitar una atención destacada preferentemente dentro del contexto del escándalo o la denuncia (caso Piñera, localización del parlamento, monto de las dietas, viajes, partes por velocidad a parlamentarios, denuncia de tráfico de drogas en la institución, etc.).

Por otro lado, si bien se han posicionado de manera destacada los variados hechos vinculados con las relaciones cívico-militares, su tratamiento comunicacional ha sido poco transparente. Las manifestaciones de fuerza, los desacuerdos y descontentos de las fuerzas armadas han sido tratados como asuntos reservados. Lo que ha prevalecido es el discurso de la normalidad que se ha contrapuesto a las fuertes imágenes de la no normalidad. También aparece como problemático el tratamiento informativo de las cuestiones relacionadas con los derechos humanos las cuales están fuertemente relacionadas a las metas de reconciliación de los gobiernos de la Concertación. Un ejemplo paradigmático es el tratamiento comunicativo que recibe el Informe Rettig en el momento de su publicación en 1991. Este informe que constituyó el gran esfuerzo de reconocimiento de las violaciones humanas ocurridas durante la dictadura pudo haber tenido su significación mas plena en la incorporación a la memoria colectiva de acontecimientos del pasado todavía negados en la historia oficial. Sin embargo, las instancias para producir un real reconocimientos y un debate profundo no se dieron. La publicidad del informe Rettig se dio en los límites fijados por el consenso negociado entre la Concertación, las fuerzas armadas, la derecha y la Iglesia Católica. Los grupos de la izquierda concertacionista estuvieron más preocupados de evitar roces con las fuerzas armadas y el 
poder judicial que de poner verdaderamente en el tapete público las visiones sobre sucesos en los que se vieron involucradas sus propias sobrevivencias e identidades históricas. A la instauración de esta suerte de voz única se sumaron la gran mayoría de los medios de prensa los cuales, fieles a los intereses ideológicos de sus grupos de pertenencia, no dieron una real cabida ni propiciaron instancias de confrontación del discurso dominante con los de aquellos pocos grupos que se desviaban de las posturas "reconciliadoras" oficiales.

Pero el problema no fue únicamente el predominio de un discurso político lo más aséptico posible y desprovisto de aristas conflictivas. El poco conocido, en sus reales contenidos, Informe Rettig (pues las informaciones se centraron más en las reacciones de los sectores involucrados que en dar a conocer las violaciones allí consignadas) no impulsó un debate nacional acerca de temáticas tan fundamentales como los derechos inalienables del ser humano, o los valores de la verdad y la justicia. Tampoco se le proporcionó a la sociedad chilena relatos dramatizados donde se vieran contextualizadas en tramas vivenciales e imágenes las traumáticas experiencias del pasado. Sólo los últimos años, y en gran medida motivado por la detención del General Pinochet en Londres, empezaron a circular en los medios, sobre todo en la televisión, visiones relacionadas con los valores de la verdad y la justicia y rostros, sentimientos, recuerdos que han contribuido a producir una conciencia públicamente compartida, aunque no necesariamente coincidente, acerca de sucesos del pasado.

A manera de conclusión, podemos decir que la representación que se le ha ofrecido a los chilenos durante los seis primeros años de los Gobiernos de la Concertación ha sido sesgada e incompleta. A través de la agenda informativa de los medios se ha proporcionado la visión de un país centrado en lo económico, en el éxito individual logrado a través de su participación en el mercado y en el bienestar derivado de la maximización del consumo privado. Han faltado discursos políticos interpretativos y proyectivos en los cuales haya estado presente la prefiguración del ciudadano en tanto actor fundamental y responsable de la constitución y preservación del orden social. Ha habido ausencia de nociones y valores fundamentales para el logro de democracias inclusivas como la noción del bien común y la valoración de lo colectivo como componente esencial del progreso individual y social. Por otro lado parece problemático que las significaciones de las gestas competitivas colectivas y la señalización ética del mal, elementos que siempre han estado presentes en los discursos públicos y son parte esencial de la representación que las sociedades hacen de sí mismas, se haya realizado de modo principal en los ámbitos deportivos y delincuenciales y escasamente dentro de lo político, lo social y lo cultural.

\section{El escenario comunicacional actual}

Cualquiera que se asome a la realidad nacional que actualmente prefiguran los medios masivos puede constatar que está es muy diferente a aquella que primó durante los primeros años de la transición. Los chilenos se enfrentan a un entorno en el que parecen sobresalir los problemas no resueltos por sobre las metas alcanzadas. Durante lo que va corrido del año 2000 nos hemos visto permanentemente expuestos al espectáculo de la pobreza y el subdesarrollo encarnado en la precariedad habitacional de muchas familias, en la cesantía sin resguardos mínimos, en las deficiencias en el sistema de salud y educacional, etc. Se ha hecho evidente que muchos habitantes de este país no alcanzan los bienestares mínimos necesarios para una vida digna. Por otro lado, cuestiones como los cobros excesivos de intereses, el no cumplimiento de normas en la construcción, las falencias y falta de control respecto a la calidad de los alimentos, entre otros problemas, han puesto un fuerte acento en los problemas de la indefensión ciudadana. Estas informaciones muestran una sociedad que carece de las herramientas o de las capacidades para asegurar sus derechos civiles y oponerse a las prácticas abusivas. Junto con lo anterior podemos observar un aumento de la conflictividad social y política que se manifiesta principalmente como "reclamos" a un gobierno que, según los discursos establecidos, debería por si sólo ser capaz de proporcionar soluciones a todos los distintos problemas.

Si nos situamos en el ámbito político, nos encontramos ante una Concertación a la defensiva frente a un creciente discurso polarizador de la derecha, que no escatima sus acusaciones y 
ha entrado en una escalada de descalificación. Lo que está claro es que las lógicas de consenso ya no están operantes, no porque el conglomerado en el poder haya dejado de buscar los acuerdos sino porque la oposición no está interesada en lograrlos.

La pregunta es hasta que punto el cuadro de ineficacia e ingobernabilidad que la derecha con el apoyo incondicional de muchos medios de prensa trata de establecer afectará la percepción de los ciudadanos. Al parecer hasta ahora el gobierno ha logrado mantener cuotas importantes de credibilidad y confianza social y responder a las esperanzas de cambios que se han hecho fuertemente presentes en la ciudadanía. Sin embargo, es difícil evaluar si una sociedad privada durante mucho tiempo de los parámetros de comprensión e interpretación que proporciona la circulación de debates y discursos políticos prefigurantes podrá ejercer sus derechos ciudadanos y contribuir al desarrollo del sistema democrático sin caer irremisiblemente en el influjo de discursos populistas altamente efectistas. La pregunta es hasta que punto sigue vigente un imaginario y una conciencia política que indudablemente fue importante en el pasado democrático y en la dictadura. Podrá esta conciencia social y política hacer pesar principios y responsabilidades democráticas en la formulación de las legítimas demandas y revindicaciones frente a problemas concretos y urgentes. Por último, uno se puede interrogar acerca de la influencia que tendrán en las orientaciones políticas de los chilenos las memorias de comportamientos y utopías del pasado que todavía pueden conservarse. Memorias que han sido de alguna manera avivadas por la presencia en las agendas informativas del Caso Pinochet, como asimismo por hechos relacionados con la Colonia Dignidad, el Plebiscito del 80, los documentos desclasificados de la CIA, el paro de los camioneros, etc. 